\title{
Our experiences with the surgical repair of traumatic vascular injuries
}

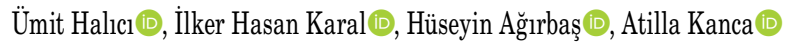 \\ Department of Cardiovascular Surgery, Samsun Training and Research Hospital, Samsun, Turkey
}

\begin{abstract}
Objectives: The aim of this study is to report our experiences about the surgical repair of traumatic vascular injuries.

Patients and methods: Between January 2011 and July 2019, 164 patients (151 males, 13 females; mean age $35.6 \pm 13.8$ years; range, 6 to 77 years) who underwent emergency surgery due to vascular injuries were included in this retrospective study. Operative techniques, causes for injury, and patient outcomes were analyzed. Data were collected from the patient records.

Results: Repair for major arterial injury was performed in 149 patients and 59 of them had a major venous injury. Of 149 patients, 18 had an only major arterial injury. Seven patients had an only major venous injury. Exploration and ligation of bleeding of the small arteries and veins were performed in eight patients. Primary repair with end-to-end anastomosis in 85 arterial and 20 venous injuries was performed. Autologous vein graft interpositioning was performed in 36 arterial and 16 venous injuries. Lateral wall repair was performed in nine arterial and eight venous injuries. Ligation was performed in 25 arterial and 20 venous injuries. An 8-mm biological graft interpositioning was performed to both popliteal artery and popliteal vein in one patient with a gunshot wound. Externally supported polytetrafluoroethylene synthetic graft interposition was performed in five arterial injuries. A 6-mm Dacron graft was placed in one patient. Thoracic endovascular aorta repair was performed in one patient with a descending thoracic aortic rupture.
\end{abstract}

Conclusion: Peripheral vascular injuries should be kept in mind in trauma patients and detected vascular injuries should be repaired as soon as possible after a detailed vascular examination.

Keywords: Sharp injury, traumatic vascular injury, vascular surgery.

Traumatic vascular injuries pose various problems to vascular surgeons in emergency services. Vascular injuries consist approximately 2 to $3 \%$ of all trau matic injuries. ${ }^{[1]}$ It is well-known that good survival after vascular trauma depends on early diagnosis and treatment of vascular injury. The location of the trauma and the features of injured tissue are important for the survey of the injury. ${ }^{[2]}$ Major vascular injuries can cause significant consequences such as functional deficits, loss of limb, and dead. Moreover, concomitant injuries of patient with vascular trauma may play an important role in morbidity and mortality. ${ }^{[1]}$ Therefore, systemic evaluation is important, as well as vascular evaluation. ${ }^{[1]}$ There are many causes of vascular injury such as sharp injuries, blunt injuries, and gunshot injuries.

In this study, we report our experience about the surgical repair of traumatic vascular injuries.

\section{PATIENTS AND METHODS}

Between January 2011 and July 2019, 164 patients (151 males, 13 females; mean age $35.6 \pm 13.8$ years; range, 6 to 77 years) who underwent emergency surgery due to vascular injuries were included in this singlecenter, retrospective study. The patients were admitted to the emergency department of our hospital for peripheral vascular injuries. In multi-trauma patients,

Received: February 28, 2020 Accepted: March 23, 2020 Published online: April 13, 2020

Correspondence: Ümit Halıcı, MD. Samsung Eğitim ve Araştırma Hastanesi Kalp ve Damar Cerrahisi Kliniği, 55090 İlkadım, Samsun, Türkiye. e-mail: uhalici2003@yahoo.com 
a thorough systemic examination was performed by associated branch physicians in the trauma room. If additional pathologies were detected after the initial evaluation, patients were operated by these branches. Data were collected using the patient records. A written informed consent was obtained from each patient. The study protocol was approved by the Samsun Training and Research Hospital Ethics Committee. The study was conducted in accordance with the principles of the Declaration of Helsinki.

For vascular injuries, a detailed examination was performed in the emergency room. Main symptoms and complaints were bleeding, hypotensive shock, pain, unpalpable distal pulses, and coldness of fingers. Patients with abundant bleeding, deep hypotension or shock, unstable vital signs and open injuries were operated after the physical examination as soon as possible without any further investigation. We used blood products which were erythrocyte suspension and fresh blood as needed in patients with multi-trauma patients. These patients had hemoglobin values below $8 \mathrm{~g} / \mathrm{dL}$, unstable vital signs, and active bleeding. Fresh frozen plasma was also indicated for the deficiency of coagulation factors in the presence of active bleeding. The diagnosis of vascular injury was confirmed by computed tomography angiography (CTA) in most patients with stable vital signs and they were, then, taken into emergency operation.

General anesthesia was preferred in the vast majority of cases, while local anesthesia was preferred in isolated superficial vascular injuries of the extremities such as radial, ulnar artery, and anterior/posterior tibial artery injuries. In patients with bone fractures, fixation of fractures was made by an orthopedic surgeon initially and vascular repair performed later. On the other hand, vascular repair was first performed in patients with hemodynamically unstable or delayed patients. Direct repair of arterial injuries was often preferred. During the operation, when primary repair was not possible for traumatized vessels due to the tissue loss of vessel, autogenous saphenous vein grafts harvested from non-traumatized extremities were used. This condition was frequently found in patients with gunshot injuries. When the saphenous vein grafts were ineligible, synthetic or biologic grafts were used in these patients. Concomitant venous injuries were detected during surgery in selected patients. Main adjacent venous injuries were also repaired as much as possible for saving the extremity. All multi-trauma patients were followed in our intensive care unit after the operation. Then, they were transferred to the ward, when their general condition improved and their vital signs became stable.

Fasciotomy was performed at the time of surgery for prophylaxis of the compartment syndrome in five patients with a 6 -h interval between the initial vascular trauma and vascular repair. Also, fasciotomy due to compartment syndrome was performed in four patients in the early postoperative period and these patients were transferred to plastic surgery clinic after the completion of vascular surgery. In patients with fasciotomy, eight of them had a lower limb vascular injury and one patient had an upper extremity vascular injury. In the postoperative first three days, low-molecular-weight heparin (LMWH) (twice a day, according to the patient's body weight) was given to all patients for vascular patency and prophylaxis of deep vein thrombosis (DVT). Meanwhile, postoperative control Doppler ultrasound (DUS) was made. If the repaired vessels were open and there was no DVT, antiaggregant treatment (oral acetylsalicylic acid or clopidogrel) was initiated and the LMWH dose was reduced for prophylaxis of DVT (once a day, according to the patient's body weight). Later, anticoagulant treatment was discontinued and the patients were discharged. If an occlusion in the repaired vessels was detected, the patient was taken to revision surgery. If there were patency in the repaired vessels with DVT, oral warfarin sodium was started. There was no referral to another hospital for vascular injuries or complications. Operative techniques, causes of injury, and patient outcomes were reviewed.

\section{Statistical analysis}

Statistical analysis was performed using the Microsoft Excel version 2013 software (Microsoft Corp., WA, USA). Descriptive data were expressed in mean \pm standard deviation (SD), median (min-max) or number and frequency.

\section{RESULTS}

Repair for major arterial injury was performed in 149 patients and 59 of them had a major venous injury and underwent venous repair. Of 149 patients, 18 had an only major arterial injury. Seven patients had an only major venous injury and these injuries were repaired. Exploration and ligation of bleeding of small arteries and veins were performed in eight patients after the traumatic injury. Injured main arteries and veins are shown in Table 1 and Table 2, respectively. In addition, there were lots of concomitant small vein 


\begin{tabular}{|c|c|c|}
\hline Location of arterial injury & $\mathrm{n}$ & $\%$ \\
\hline Descendant thoracic artery & 1 & 0.62 \\
\hline External iliac artery & 3 & 1.86 \\
\hline Internal iliac artery & 1 & 0.62 \\
\hline Common femoral artery & 2 & 1.24 \\
\hline Superficial femoral artery & 26 & 16.15 \\
\hline Deep femoral artery & 4 & 2.49 \\
\hline Popliteal artery & 21 & 13.05 \\
\hline Posterior tibial artery & 9 & 5.59 \\
\hline Anterior tibial artery & 9 & 5.59 \\
\hline Fibular (peroneal) artery & 6 & 3.73 \\
\hline Dorsalis pedis artery & 2 & 1.24 \\
\hline Axillary artery & 3 & 1.86 \\
\hline Subclavian artery & 2 & 1.24 \\
\hline Brachial artery & 12 & 7.46 \\
\hline Ulnar artery & 13 & 8.08 \\
\hline Radial artery & 37 & 22.98 \\
\hline Common carotid artery & 2 & 1.24 \\
\hline Internal carotid artery & 3 & 1.86 \\
\hline External carotid artery & 1 & 0.62 \\
\hline Obturator artery & 1 & 0.62 \\
\hline Right internal mammary artery & 2 & 1.24 \\
\hline Intercostal artery & 1 & 0.62 \\
\hline
\end{tabular}

injuries in the extremities and these veins were not shown in this table for easy understanding of vascular injuries. The mechanisms of injuries are shown in Table 3. The mean Glasgow Coma Score of the patients was $12.8 \pm 3.2$.

Primary repair with end-to-end anastomosis in 85 arterial and 20 venous injuries was performed. Autologous vein graft interpositioning was performed in 36 arterial and 16 venous injuries. In these patients, vena saphena magna, basilic vein, and superficial forearm veins were used as a graft in 34 , one, and one arterial injuries, respectively and vena saphena magna was used as a graft in all venous injuries. These autologous veins were usually harvested from non-traumatized contralateral extremities. Lateral wall repair was performed in nine arterial and eight venous injuries. Saphenous patch plasty was performed in one arterial injury. Ligation was performed in 25 arterial and 20 venous injuries. Ligated arteries and veins were often located in the distal part of the extremities and they were unsuitable for repair. Also, these vessels had tissue loss. An 8-mm biological graft interpositioning
Table 2. Location of venous injuries

\begin{tabular}{lcc}
\hline Location of venous injury & $\mathrm{n}$ & $\%$ \\
\hline Intercostal vein & 1 & 1.51 \\
Right internal mammary vein & 2 & 3.02 \\
Axillary vein & 2 & 3.02 \\
Antecubital vein & 1 & 1.51 \\
Basilic vein & 1 & 1.51 \\
Cephalic vein & 3 & 4.53 \\
Internal jugular vein & 4 & 6.04 \\
Vena cava inferior & 1 & 1.51 \\
External iliac vein & 2 & 3.02 \\
Common femoral vein & 1 & 1.51 \\
Superficial femoral vein & 22 & 33.43 \\
Profunda femoral vein & 4 & 6.04 \\
Popliteal vein & 20 & 30.33 \\
Vena saphena magna & 1 & 1.51 \\
Vena saphena parva & 1 & 1.51 \\
\hline
\end{tabular}

\begin{tabular}{lcc} 
Table 3. The mechanism of injury of patients & & \\
\hline Injury mechanism & $\mathrm{n}$ & $\%$ \\
\hline Stab wound & 100 & 60.97 \\
Gunshot wound & 51 & 31.09 \\
Traffic accident & 6 & 3.85 \\
Crush injury & 4 & 2.80 \\
Fall & 2 & 1.22 \\
Ox horning & 1 & 0.07
\end{tabular}

was performed to both popliteal artery and popliteal vein in one patient with a gunshot wound. Externally supported (ringed) polytetrafluoroethylene (PTFE) synthetic graft interposition was performed in five arterial injuries (four PTFE grafts were $6 \mathrm{~mm}$ and the last one was $8 \mathrm{~mm}$ ). The PTFE grafts of $8 \mathrm{~mm}$ and $6 \mathrm{~mm}$ sizes were placed in two venous injuries. In addition, 6- $\mathrm{mm}$ Dacron graft interpositioning was performed to both popliteal artery and popliteal vein in one patient.

Among the patients, two with a gunshot wound underwent second operation in the postoperative first day. Replacement of occluded interposition saphenous vein grafts which were used in the first operation for the injured popliteal artery and vein was performed with a size of 6-mm PTFE graft and 6-mm Dacron graft. In addition, aorta-to-left subclavian artery bypass was performed with a 6-mm PTFE graft via median sternotomy in one patient with a stab wound injury. Ten arterial thrombectomies were 
additionally performed in selected patients during the operations. Also, thoracic endovacular aortic repair (TEVAR) was performed in one patient with a descending thoracic aortic injury (contained rupture) next to the left subclavian artery origin due to traffic accident.

External fixators and splints were applied in 11 and 17 patients by an orthopedic surgeon, respectively. In patients with external fixators, six, three, and two patients had a femoral, tibial, and humeral fracture, respectively. Also, in patients with splints, two and 15 had a long leg splint and long arm splint, respectively. Minimally invasive percutaneous plate osteosynthesis was applied in two patients with a femoral fracture. In selected patients, nerve injuries and tendon and muscle injuries were evaluated and repaired by the hand surgery, orthopedic surgery, and plastic surgery departments.

Above-knee amputation was performed in two patients who had a gunshot wound of the popliteal region. These patients had also multiple fragmented femoral fractures and compartment syndrome and, therefore, external fixators and fasciotomy were applied, respectively. Abundant bleeding, irreversible severe ischemia of the distal part of the extremity, severe compartment syndrome despite fasciotomy and occlusions of the grafts in both popliteal artery and popliteal veins were detected at one week after the initial operation and, therefore, reintervention was not suitable for these patients.

Mortality was observed in five patients. All were previously operated for gunshot wounds $(n=3)$, stab wounds $(n=1)$, and fall from a height $(n=1)$. These patients had multisystem and vascular traumas.

\section{DISCUSSION}

Trauma is a life-threatening major public health problem which is common among the young population in developed and developing countries. ${ }^{[3]}$ However, traumatic vascular injuries are infrequent, but can be devastating. ${ }^{[4]}$ Unfortunately, at the present time, vascular injuries progressively increase. ${ }^{[5]}$ Increasing armament, terrorist incidents and wars, and traffic and occupational accidents lead us to encounter more often peripheral vascular injuries. ${ }^{[6]}$

At present, vascular injuries often occur with penetrating traumas (stab wound injuries), followed by gunshot injuries. ${ }^{[7]}$ Becit et al. ${ }^{[8]}$ reported that most of the vascular injuries were penetrating vascular injuries and gunshot injuries and their rates were $52.8 \%$ and
27.4\%, respectively. Similarly, Ozkekeli et al..$^{[9]}$ found the rates of penetrating vascular injuries and gunshot wounds to be $60 \%$ and $22.5 \%$, respectively. In this study, the rates of penetrating injuries and gunshot wounds were $60.97 \%$ and $31.09 \%$, respectively and these results are consistent with the literature.

Early diagnosis is the key to appropriate management of arterial and venous injuries. ${ }^{[10]}$ Physical examination is critical in the diagnosis of patients with suspected vascular injuries. Mataraci et al. ${ }^{[11]}$ reported that early surgical intervention, extent and site of the trauma, and presence of concomitant injured structures in addition to vascular injuries were the most important factors affecting the morbidity and the mortality of the vascular trauma patients.

In a review, Feliciano ${ }^{[12]}$ reported that the goal of the general surgery trauma team was to analyze whether a peripheral vascular injury was present in any hemodynamically stable patients with trauma to an extremity. Diagnostic methods such as CTA, DUS, and conventional angiography can be used in hemodynamically stable patients. On the other hand, Nitecki et al. $^{[13]}$ recommended that CTA was the first-line assessment modality for the diagnosis of a vascular injury in trauma patients. Genovese et al. ${ }^{[14]}$ showed that CTA allowed a rapid, accurate, non-invasive method for detecting vascular injuries. Several studies also reported that CTA became the gold standard for the diagnosis of vascular injuries. ${ }^{[15,16]}$ Thus, we preferred CTA as the first-line diagnostic modality in most patients with suspected vascular injuries after physical examination. Then, we decided the treatment of these patients.

Treatment of traumatic vascular injuries necessitates an emergency vascular surgery and appropriate surgical repair. In certain patients, an emergency operation without using an advanced imaging modality may be considered in trauma patients with active pulsatile external bleeding, hemodynamic shock or hemodynamic instability with a probability of internal bleeding and absent pulses. We applied pressure or tourniquet in the emergency room to control bleeding in patients with active externalbleeding from the extremities. Thus, excessive blood loss may be the cause of mortality. ${ }^{[17,18]}$ Early intervention is of utmost importance in extremity traumas with peripheral vascular injuries. ${ }^{[19]}$ In our study, we also performed an emergency operation for our patients in this manner. Similarly, 25 patients had hypotension and shock and underwent emergency 
surgery as soon as possible without any diagnostic investigation.

Ustunsoy et al. ${ }^{[20]}$ emphasized the importance of concomitant venous repair and early intervention in combined arterial and venous injuries. Tünerir et al. ${ }^{[21]}$ reported that early diagnosis and adequate therapy played an important role in salvation of the extremity after peripheral artery injuries. They also reported that injured veins should be repaired as well as injured arteries to increase the success of intervention in peripheral vascular injuries. ${ }^{[21]}$ Kayalar et al. ${ }^{[22]}$ also found that, if a conduit was required, they preferred an autologous vein as the vascular conduit for extremity injuries and mostly used the contralateral leg for harvesting to prevent venous stasis of the affected extremity. However, the authors reported that an expanded PTFE graft was used in selected cases with no available autologous vein graft and non-contaminated blunt injuries. In this study, in patients with arterial and venous injuries, venous injury was repaired first and, then, arterial injury was repaired. We often ligated injured small veins to control bleeding. In cases of a suspicion of thrombosis distal or proximal to the arterial injury, embolectomy was performed before the completion of repair. Thus, we performed embolectomy before the completion of the arterial repair in selected 10 patients.

On the other hand, over the past several decades, endovascular techniques have become an important treatment option in acute trauma patients. The management of vascular injuries with endovascular techniques have been used in an increasing frequency in recent years. ${ }^{[23]}$ Endovascular interventions can be preferred in selected vascular trauma patients. Uguz et al. ${ }^{[24]}$ reported that endovascular procedures could offer a less invasive alternative to treat those injuries with a lower rate of morbidity and mortality. In this study, we operated all patients, except for one patient who underwent TEVAR for a descending thoracic aortic injury.

It should be kept in mind that some patients with additional non-vascular pathologies may require additional interventions. Bishara et al. ${ }^{[25]}$ reported that vascular injuries of the extremities associated with fractures and dislocations had a high potential for morbidity and amputation rates of the patients ranged from 10 to $40 \%$ in civilian series. Similarly, Engin and Aydin ${ }^{[19]}$ reported that, when the limb trauma resulted in fractures and bone dislocations, a risk for amputation might increase up to $40 \%$. In this study, patients with tendon, muscle, bone, and nerve injuries were evaluated by specialists preoperatively or intraoperatively. Also, the patients with additional traumas were evaluated by the relevant branches and they were taken to the operation, if needed. A total of 35 patients had additional injuries except for vascular injuries and two of these patients underwent above-knee amputation after vascular surgical repair. In addition, some of the patients were transferred to other branch wards for additional pathologies after vascular repair (i.e., fasciotomy closure with skin grafting). Management of acute traumatic arterial injuries is very difficult. ${ }^{[26]}$ Therefore, despite advances in the field of treatment, these injuries are still associated with a significant loss of limb and functional deficits. ${ }^{[26]}$

Compartment syndrome was diagnosed based on the presence of edema and tenseness of the affected compartment of the traumatized extremity. Also, we found compartment-related ischemia in some patients. In our clinic, the diagnosis is mostly based on clinical criteria. On the other hand, it was reported that direct compartment pressure measurements could be used in certain clinical conditions to confirm the suspected diagnosis. ${ }^{[27]}$ In the aforementioned study, reported that fasciotomies performed within $8 \mathrm{~h}$ of arterial injury treatment which were located at extremities were associated with significantly improved limb outcomes and shortened hospital stay, compared to fasciotomies performed at later periods. ${ }^{[27]}$ In our clinic, routine fasciotomy was not performed in multi-trauma patients, except for delayed trauma cases. In patients with extremity injuries, we performed fasciotomy to treat or for the prophylaxis of the compartment syndrome in nine patients (5.4\%).

Amputation is a serious cause of morbidity due to extremity traumas. Furthermore, mortality and morbidity are the main concerns in traumatic injuries. Although mortality is a catastrophic outcome, most of the injuries occur in the young population. Limb losses and motor deficits are the major causes of morbidity. Kayalar et al. ${ }^{[22]}$ reported a mortality rate of $6.2 \%$ for emergency vascular injuries. Becit et al. ${ }^{[8]}$ reported that the rates of amputation and mortality were $3.9 \%$ and $6.1 \%$, respectively. In addition, Salimi et al. ${ }^{[28]}$ showed that the rates of amputation and mortality were $11.4 \%$ and $4.06 \%$, respectively. On the other hand, amputation and mortality rates varied between 1 and $10 \%$ and 1 and $5 \%$, respectively. ${ }^{[29]}$ In our study, we found that the 
amputation and mortality rates were $1.2 \%$ and $3 \%$, respectively.

Nonetheless, our study has some limitations. First, this study was a retrospective study and it was performed in a single-center. Second, the sample size was relatively small. Third, data on existing injuries and of patients followed for vascular injuries were limited to the period of stay in our center. Therefore, complications, mortality, and morbidity evaluation in the form of early data would be appropriate. On the other hand, we believe that the mechanism and the site of injury, presence of additional lesions, and early surgical intervention are the most important factors determining mortality and morbidity in peripheral vascular injuries. In addition, a detailed vascular examination is essential in the differential diagnosis and treatment plan.

In conclusion, peripheral vascular injuries can cause loss of extremity or can be life-threatening. Vascular injuries should be kept in mind in trauma patients and vascular injuries should be repaired as soon as possible after the detailed vascular examination.

\section{Declaration of conflicting interests}

The authors declared no conflicts of interest with respect to the authorship and/or publication of this article.

\section{Funding}

The authors received no financial support for the research and/or authorship of this article.

\section{REFERENCES}

1. Depboylu BC, Külcü N, Yolyapan DA. Our surgical experience in peripheral vascular injuries: Retrospective analysis of 45 Cases. Turk J Vasc Surg 2015;24:22-8.

2. Özgüler İM, Atlı H, Kılıç AT, Güzel G, Köşker TÖ. Our surgical experiences on vascular injuries in Afrin Olive Branch operation. Turk J Vasc Surg 2019;28:144-50.

3. Çolak A, Kaya U. Analysis of upper limb vascular injuries. Turk J Vasc Surg 2016;25:51-8.

4. He JC, Clancy K, Schechtman D, Conrad-Schnetz KJ, Claridge JA. Traumatic vascular injuries: who are repairing them and what are the outcomes? Am J Surg 2016;211:619-25.

5. Gürkan S, Gür Ö, Hüseyin S, Yüksel V, Ünal S, Ege T. Peripheric vascular injuries: 10 years experience. Turk J Vasc Surg 2012;21:34-7.

6. Alsalehi S, Taşar M, Antal Dönmez A, Tuncer A, Köksal C, Sunar H. Evaluation and surgical treatment of peripheral vascular injuries. Turk J Vasc Surg 2011;20:39-43.

7. Ünlü Y, Vural Ü, Özyazıcıŏlu A, Ceviz M, Karapolat S, Koçak H. Upper extremity vascular injuries (the evaluation of 98 cases). Turk Gogus Kalp Dama 1998;6:318-22.
8. Becit N, Ateş A, Özyazıcıoğlu A, Ünlü Y, Balcı AY, Ceviz M. Evaluation and surgical treatment in peripheral arterial injuries. Turk Gogus Kalp Dama 2000;8:540-5.

9. Ozkokeli M, Gunay R, Kayacıoğlu I, Sarıkaya S, Yazar M, Akçar M. Peripheric vascular injuries. Turk Gogus Kalp Dama 1998;6:249-53.

10. Dhillan R, Bhalla A, Kumar Jha S, Singh H, Arora A. Vascular injuries due to penetrating missile trauma in antiterrorism ops. J Trauma Inj 2019;32: 93-100.

11. Mataracı İ, Polat A, Songur M, Kıran B, Çevirme D, Sunar $\mathrm{H}$, et al. Amputation-free treatment of vascular trauma patients. Turk Gogus Kalp Dama 2010;18:17-22.

12. Feliciano DV. Pitfalls in the management of peripheral vascular injuries. Trauma Surg Acute Care Open 2017;2:e000110.

13. Nitecki SS, Karram T, Ofer A, Engel A, Hoffman A. Management of combat vascular injuries using modern imaging: are we getting better? Emerg Med Int 2013;2013:689473.

14. Genovese EA, Fonio P, Floridi C, Macchi M, Maccaferri A, Ianora AAS, et al. Abdominal vascular emergencies: US and CT assessment. Crit Ultrasound J 2013;5 Suppl 1:S10.

15. Suárez Poveda T, Morales Uribe CH, Cruz Vásquez R, Montoya Arango Mdel P, Ochoa Escudero M. Efficacy of multidetector computed angiotomography in the diagnosis of limb arterial injuries. Cir Esp 2013;91:257-62.

16. Wahlgren CM, Riddez L. Penetrating Vascular Trauma of the Upper and Lower Limbs. Curr Trauma Rep 2016;2:11-20.

17. Passos E, Dingley B, Smith A, Engels PT, Ball CG, Faidi $\mathrm{S}$, et al. Tourniquet use for peripheral vascular injuries in the civilian setting. Injury 2014;45:573-7.

18. Fansa I, Atay M, Altınay L, Saydam O, Karatepe C, Acıpayam M, et al. Analysis of vascular trauma in terrorrelated civilian attacks within south-eastern Turkey. Turk J Vasc Surg 2016;25:101-9.

19. Engin M, Aydin H. Evaluation of traumatic extremity vascular injuries in surviving and non-surviving patients. Turk J Vasc Surg 2019;28:95-100.

20. Ustunsoy H, Tuncozgir B, Sanli M, Topal M, Elbeyli L, Kanko M. Peripheral vascular injuries. Turk Gogus Kalp Dama 1999;7:140-3.

21. Tünerir B, Beşoğul Y, Yavuz T, Al-Eqaidat A, Aslan R, Kural $\mathrm{T}$, et al. Peripheral artery injuires and results of treatment. Turk Gogus Kalp Dama 1998;6:151-4.

22. Kayalar N, Boyacıŏlu K, Ketenciler S, Kuplay H, Mert B, Yücel C, et al. Emergency vascular injuries: patient profile, management strategies and risk factors for mortality. Turk Gogus Kalp Dama 2017;25:74-81.

23. Johnson CA. Endovascular management of peripheral vascular trauma. Semin Intervent Radiol 2010;27:38-43.

24. Uğuz E, Eşref Erdoğan K, Boysan E, Canyiğit M, Ali S, Erdoğan M, et al. Endovascular repair of arterial injuries as a complication of spinal surgery. Turk J Vasc Surg 2018;27:42-6.

25. Bishara RA, Pasch AR, Lim LT, Meyer JP, Schuler JJ, Hall $\mathrm{RF} \mathrm{Jr}$, et al. Improved results in the treatment of civilian vascular injuries associated with fractures and dislocations. J Vasc Surg 1986;3:707-11.

26. Yilmaz S, Ece Nazlı Y, Zehir S, Sarak T, Yilmaz C. Vascular injuries and their results in patients with penetrating 
extremity trauma. Turk J Vasc Surg 2015;24:110-8.

27. Farber A, Tan TW, Hamburg NM, Kalish JA, Joglar F, Onigman T, et al. Early fasciotomy in patients with extremity vascular injury is associated with decreased risk of adverse limb outcomes: a review of the National Trauma Data Bank. Injury 2012;43:1486-91.
28. Salimi J, Karbakhsh MR. Zarei RM. Vascular injuries in Tehran: A review of 123 cases. Acta Med Iran 2006;44:333-40. 29. Burma O, Uysal A, Özsin KK, Tok R, Köksal H, Rahman A. Our surgical experience with peripheral vascular injuries: Evaluation of 175 patients. Turk Gogus Kalp Dama 2005;13:252-4. 